\title{
Single Incision Laparoscopic Surgery for Small Bowel Tumor
}

\author{
Jung-Young Ahn, M.D., Eun-Young Kim, M.D., Bong-Hyeon Kye, M.D., Ph.D., \\ Hyung-Jin Kim, M.D., Ph.D., Hyeon-Min Cho, M.D., Ph.D. \\ Department of Surgery, St. Vincent's Hospital, College of Medicine, \\ The Catholic University of Korea, Suwon, Korea
}

Purpose: For exact diagnosis and treatment, exploratory laparotomy is usually needed. The aim of this study was to verify the usefulness of single incision laparoscopic surgery for small bowel resection.

Methods: Five patients who underwent single incision laparoscopic surgery for small bowel tumor at our hospital from April 2010 to September 2011 were analyzed retrospectively.

Results: There were three male and two female patients. The mean age of patients was 55 years. The mean body mass index was $23.6 \mathrm{~kg} / \mathrm{m}^{2}$. The largest diameter of the tumor ranged from 1.2 to $7.7 \mathrm{~cm}$. The length of incision ranged from 3 to $6.5 \mathrm{~cm}$ (mean, $4.3 \mathrm{~cm}$ ). The Octoport (Dalim, Seoul, Korea) was used in three cases, and a glove-port or SILS port was used in the other cases. After the whole abdominal exploration and localization of the tumor, the small bowel, including the tumor, was resected and end to end anastomosis was made extracorporeally. The mean operation time was 111.8 minutes. The mean length of hospital stay was 7.2 days. There was no occurrence of postoperative complication. Histologically, two tumors were diagnosed as gastrointestinal stromal tumors, and the other three patients were diagnosed as heterotopic pancreas, lipoma, and diffuse large B cell lymphoma, respectively.

Conclusion: Single incision laparoscopic surgery is very useful for localization and resection of small bowel tumors. Compared to conventional laparoscopic surgery, it can reduce the number of trocars without increased difficulty. Small bowel tumor can be a suitable indication for single-incision laparoscopic surgery.

Key words: Small bowel tumor, Single incision laparosocpic surgery

\section{INTRODUCTION}

The tumors of small bowel are a much more significant challenge in terms of diagnosis and management than those of stomach or colon. The small bowel tumors often present with obstruction or obscure bleeding. An extensive gastrointestinal evaluation is usually required before a diagnosis is obtained. However, the diagnosis and localization of the small bowel tumors remain a clinical challenge, because of the inaccessibility of the lesion by conventional diagnostic modalities such as endoscopy. Therefore, exploratory laparotomy is usually needed for exact diagnosis and treatment.

Recently, surgery is rapidly progressing to the minimally invasive surgery, after the first laparoscopic appendectomy by Semm in 1983 and laparoscopic cholecystectomy by Mouret in 1987 [1,2]. To reduce the number of trocars, more minimally invasive surgery, single incision laparoscopic surgery is in-

Received March 26, 2014, Revised May 27, 2014,

Accepted June 2, 2014

※ Corresponding author: Hyung-Jin Kim

Department of Surgery, St. Vincent's Hospital, College of Medicine, The Catholic University of Korea, 93, Jungbu-daero, Paldal-gu, Suwon 442-723, Korea

Tel : +82-31-249-8303, Fax : +82-31-247-5347

E-mail : hj@catholic.ac.kr troduced in many different kinds of procedures such as appendectomy, cholecystectomy, hysterectomy, nephrectomy and colon resection [3-12].

However, there are several advantages and disadvantage of single incision laparoscopic surgery. This technique is more cosmetic than conventional laparoscopic surgery, and it can reduce the number of trocars and trocar-related complications. But the surgical technique is more difficult, and sometimes special instruments such as articulating instruments are needed $[4,7,11,12]$.

Although there are many report of the feasibility of single incision laparoscopic surgery, the most useful procedures for single incision laparoscopic surgery is not determined yet. Therefore we tried to found out the benefit and disadvantage of single incision laparoscopic surgery in small bowel tumor diseases.

\section{MATERIALS AND METHODS}

Five patients who underwent single incision laparoscopic surgery for small bowel tumors at our hospital between April 2010 and September 2011 were analyzed retrospectively.

The patient was performed operation using a single-port device through a transumbilical skin incision and the incision was extended according to the tumor size. Surgical procedures were 
Table 1. A summary of the patients

\begin{tabular}{ccccccccccc}
\hline No & Sex & Age & $\begin{array}{c}\text { BMI } \\
\left(\mathrm{kg} / \mathrm{m}^{2}\right)\end{array}$ & $\begin{array}{c}\text { Previous operation } \\
\text { history }\end{array}$ & $\begin{array}{c}\text { Tumor } \\
\text { size }(\mathrm{cm})\end{array}$ & $\begin{array}{c}\text { Wound } \\
\text { length }(\mathrm{cm})\end{array}$ & Instruments & \multicolumn{2}{c}{$\begin{array}{c}\text { Operative Hostipal } \\
\text { time (min) stay (day) }\end{array}$} & Patholgy \\
\hline 1 & F & 51 & 25.55 & Cesarian section & 7.7 & 4.0 & Octoport & 140 & 8 & GIST, intermediate risk \\
2 & M & 49 & 23.37 & & 1.2 & 3.0 & Octoport & 95 & 10 & Heterotopic pancreas \\
3 & F & 66 & 24.77 & Total hysterectomy & 6.0 & 6.5 & Octoport & 134 & 7 & GIST, high risk \\
4 & M & 62 & 20.08 & & 4.0 & 4.5 & SILS & 80 & 5 & Lipoma \\
5 & M & 48 & 24.09 & & 4.0 & 3.5 & Glove-port & 110 & 6 & Malignant lymphoma \\
\hline
\end{tabular}

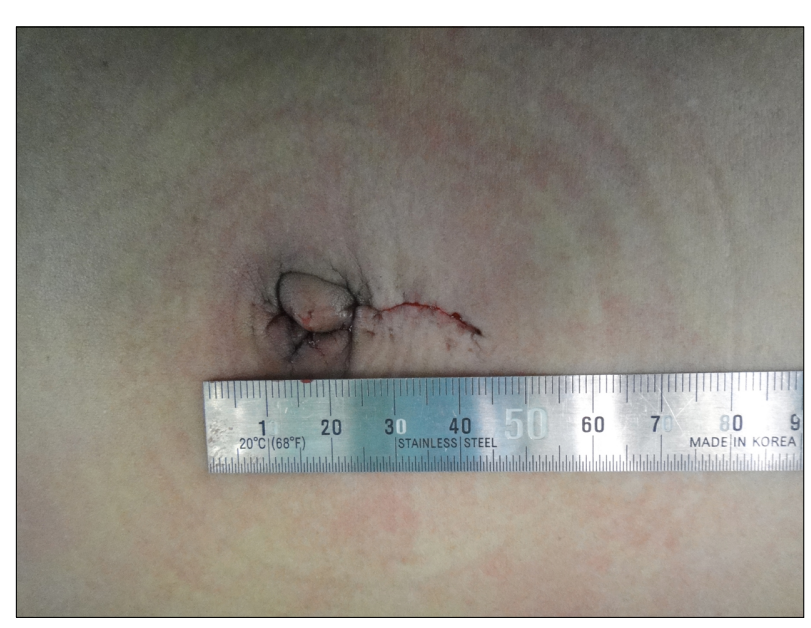

Fig. 1. The postoperative transumbilical wound.

performed under general anesthesia. The single-port device was selected according to the surgeon's choice. An Octoport (Dalim, Seoul, Korea) was used in 3 cases, and a glove-port or a SILS port was used in the other cases. A Glove-port was made before the operation [7]. As the surgical glove has five finger tips, we can use this tips freely for the purpose of trocars or other use. We used $\mathrm{CO}_{2}$ gas to keep intraabdominal presseure as $12 \mathrm{mmHg}$. The surgery was performed with the surgeon and the scopist positioned on the left side of the patient, with the first assistant placed on the right. We used a rigid $10 \mathrm{~mm}$ scope (Stryker, Kalamazoo, MI, USA) in all cases. We explored the whole abdomen and find out the location of the tumor by using the standard laparoscopic instrument. And then, the specimen was retrieved through the umbilical skin incision. The small bowel including the tumor was resected and end to end anastomosis was made extracorporeally.

\section{RESULTS}

The data of the patients are shown in Table 1. There were three male and two female patients. The mean age was 55 years (range, $51 \sim 66$ years). The mean body mass index (BMI) was

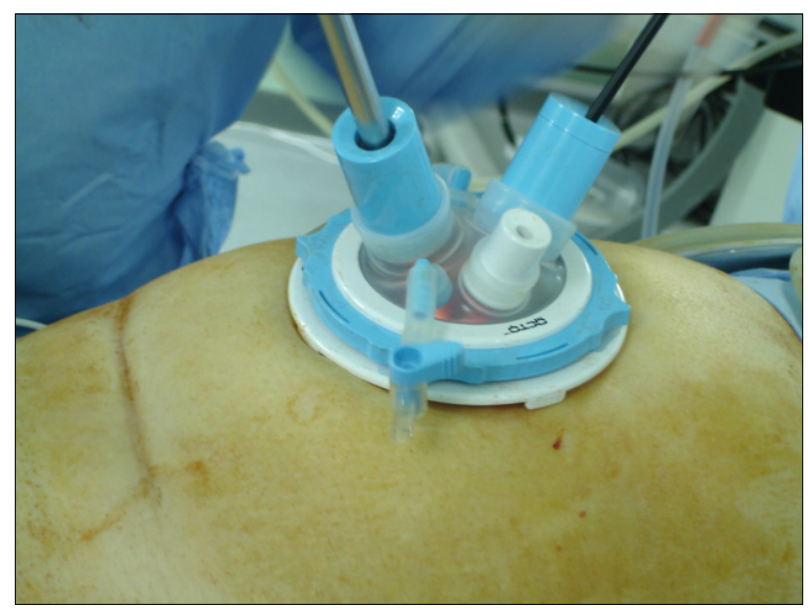

Fig. 2. An OCTO port.

$23.6 \mathrm{~kg} / \mathrm{m}^{2}$ (range, $20.1 \sim 25.6 \mathrm{~kg} / \mathrm{m}^{2}$ ). Among the patients, 2 patients have a history of previous abdominal operation, a Cesarean section and total hysterectomy, respectively. The largest diameter of tumor was ranged from $1.2 \mathrm{~cm}$ to $7.7 \mathrm{~cm}$ (mean, $4.6 \mathrm{~cm}$ ). Transumbilical skin insicion was made and extended according to the tumor size. The length of skin incision was ranged from $3 \mathrm{~cm}$ to $6.5 \mathrm{~cm}$ (mean, $4.3 \mathrm{~cm}$ ) (Fig. 1). The Octoport (Dalim, Korea) was used in 3 cases, and a glove-port or a SILS port was used in the other cases (Fig. 2). The whole intra-abdominal exploration was performed and localization of the small bowel tumor was made using standard laparoscopic instruments. After small bowel extraction including the tumor through a transumbilical skin incision, the small bowel tumor was resected and end-to-end anastomosis was made extracorporeally (Fig. 3). The mean operation time was $111.8 \mathrm{mi}-$ nutes (range, 80 140 minutes). The mean hospital stay was 7.2 days (range, $5 \sim 10$ days). All cases were completed successfully without conversion to open or multiport laparoscopic procedures. There was no postoperative complication. Histologically, two tumors were diagnosed as gastrointestinal stromal tumors. As for other three patients, heterotopic pancreas, lipoma and diffuse large B cell lymphoma was diagnosed, respectively 


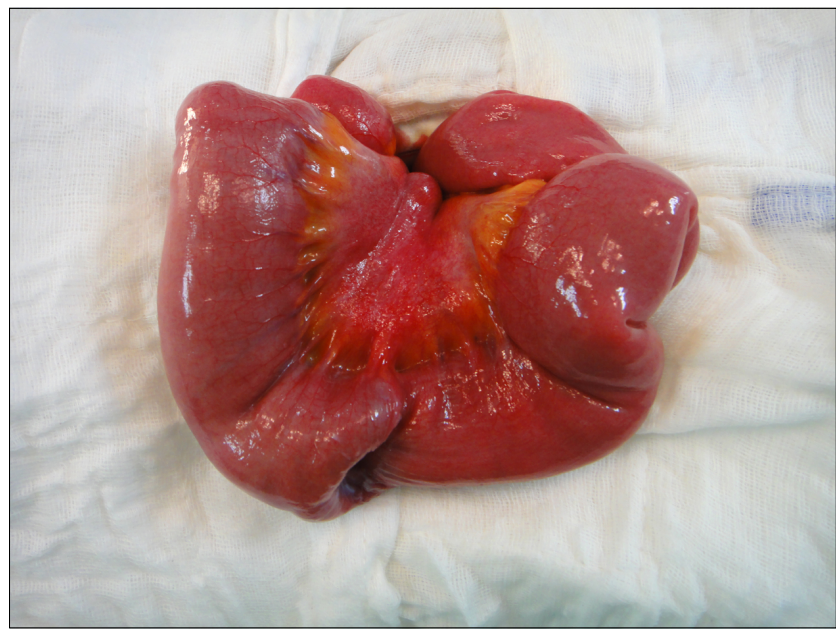

Fig. 3. The specimen of small bowel tumor.

(Table 1).

\section{DISCUSSION}

Small bowel represents the longest part of the digestive tract, making up $75 \%$ of the length (about $6 \mathrm{~m}$ long and 4 times as long as colon) and $90 \%$ of the absorptive surface area of the gastrointestinal tract. It has three sections: the duodenum, jejunum and ileum [13]. Tumors of small bowel offer a unique challenge. As a result of their infrequent incidence, they invariably present difficult problems in diagnosis and management [14]. Benign small bowel tumors are comprised of leiomyoma, lipoma, hamartoma, and desmoid tumor. Primary malignancies of small bowel are comprised of adenocarcinoma, leiomyosarcoma, carcinoid, gastrointestinal stromal tumor and lymphoma [15]. Although the prognosis for benign lesions is excellent, malignant small bowel tumors are perhaps the most devastating GI malignancies; at the time of diagnosis, only approximately $50 \%$ of these lesions are completely resectable for cure. Symptoms are often absent until the tumor has progressed to produce complications. Even then, the presentation is often vague and nonspecific, such as intermittent abdominal pain, obstruction, and chronic anemia. The cornerstone of diagnosis is the contrast radiograph. However, in practice only about $50 \%$ of these lesions are diagnosed radiographically before surgery [14]. Surgical resection of the tumor is essential for the pathological confirmation and curative treatment $[14,16]$.

The latest trend shows that surgery is rapidly progressing to the minimally invasive surgery. Minimally invasive surgery has been used for more than 30 years. Minimally invasive surgery makes the patient feel less postoperative pain, more post-

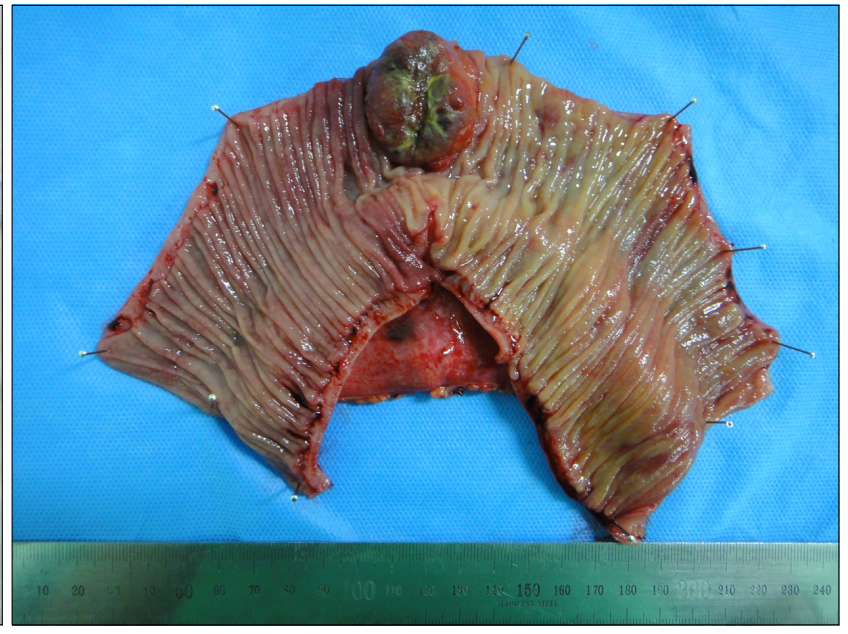

operative comfort, less hospital stay, quicker return to normal physical activities and ultimately quicker return to work [9]. The new surgical concept usually raises desire for safety, usefulness, appropriateness, applicability, and cost. This concept is reflected in the surgical techniques of NOTES (natural orifice transluminal endoscopic surgery) and single incision laparoscopic surgery $[3,7,8,17,18]$. Single incision laparoscopic surgery is to have all of the laparoscopic working ports entering the intra-abdominal cavity through the same incision. In most cases, the intraabdominal approach through the umbilicus is preferred [7]. Laparotomy has been replaced with laparoscopic surgery and would go even further single incision laparoscopic surgery. Laparoscopic surgery, especially, single incision laparoscopic surgery has many advantages to the patient in terms of improved cosmesis and reduced wound complications associated with large scars [3].

Recently, single incision laparoscopic surgery has been applied to a variety of surgical procedures such as appendectomy, cholecystectomy, colectomy, bariatric surgery, and any others $[3-12,19]$. Although most of the study report the feasibility of single incision laparoscopic surgery, only a few study report which procedure is the most appropriate for single incision laparoscopic surgery.

The present study presented the application of single incision laparoscopic surgery to small bowel resection. Single incision laparoscopic surgery is very useful and easy for localization of the small bowel tumor and it can also explore the whole abdominal cavity just like as conventional laparoscopy [16]. In addition, it can also reduce the number of the trocars. And compare to standard open surgery, it can reduce the size of incision, and easier to explore the whole intra-abdomen. These cases of 
single port small bowel resection demonstrate the feasibility and safety of this approach, which seems to offer several advantages for patients and surgeons. The technique may also be performed safely in patients with a history of previous abdominal surgery.

Single incision laparoscopic surgery has their advantages and disadvantages. Single incision laparoscopic surgery can reduce the number of trocars or the size of the incision, thereby, it makes the surgery reduce the trocar site related complication. Transumbilical single incision makes the wound smaller and more scarless in process of wound healing, as the umbilicus is depressed anatomically. So it is the most favorable to cosmesis [17]. The patient is the most satisfied with this single incision laparoscopic surgery.

On the other hand, it is technically difficult and sometimes special instruments such as articulation or curved instruments are needed [17].

However, in small bowel tumors, single incision laparoscopic surgery can overcome the weak point of single port surgery in terms of difficulty in resection and anastomosis. Because, through the skin incision (to retrieve the small bowel tumors), we can also perform the resection of small bowel and extracorporeal anastomosis easily. Technically, single incision laparoscopic surgery is not difficult for the surgeon who is skilled with conventional laparoscopic procedures.

\section{CONCLUSION}

In conclusion, small bowel tumor can be one of the suitable indications for single-incision laparoscopic surgery.

\section{REFERENCES}

1) Semm K. Endoscopic appendectomy. Endoscopy 1983;15: 59-64.

2) Litynski GS. Profiles in laparoscopy: Mouret, Dubois, and Perissat: the laparoscopic breakthrough in Europe (1987-1988). JSLS 1999;3:163-167.

3) Bucher P, Pugin F, Morel P. Single port access laparoscopic right hemicolectomy. Int J Colorectal Dis 2008;23:1013-1016.

4) Remzi FH, Kirat HT, Kaouk JH, Geisler DP. Single-port laparoscopy in colorectal surgery. Colorectal Dis 2008;10: 823-826.

5) Kuon Lee S, You YK, Park JH, Kim HJ, Lee KK, Kim DG. Single-port transumbilical laparoscopic cholecystectomy: a preliminary study in 37 patients with gallbladder disease. J Laparoendosc Adv Surg Tech A 2009;19:495-499.

6) Kim HJ, Lee JI, Lee SC, et al. Single-port laparoscopic appendectomy. J Korean Surg Soc 2010;78:338-342.

7) Kim HJ, Lee JI, Lee YS, et al. Single-port transumbilical laparoscopic appendectomy: 43 consecutive cases. Surg Endosc 2010;24:2765-2769.

8) Waters JA, Guzman MJ, Fajardo AD, et al. Single-port laparoscopic right hemicolectomy: a safe alternative to conventional laparoscopy. Dis Colon Rectum 2010;53:14671472.

9) Maggiori L1, Gaujoux S, Tribillon E, Bretagnol F, Panis Y. Single-incision laparoscopy for colorectal resection: a systematic review and meta-analysis of more than a thousand procedures. Colorectal Dis 2012;14:e643-654.

10) Fung AK, Aly EH. Systematic review of single-incision laparoscopic colonic surgery. Br J Surg 2012;99:1353-1364.

11) Kaouk JH, Haber GP, Goel RK, et al. Single-port laparoscopic surgery in urology: initial experience. Urology 2008;71:3-6.

12) Yim GW, Jung YW, Paek J, et al. Transumbilical single-port access versus conventional total laparoscopic hysterectomy: surgical outcomes. Am J Obstet Gynecol 2010;203:26.e1-6.

13) Pan SY, Morrison H. Epidemiology of cancer of the small intestine. World J Gastrointest Oncol 2011;3:33-42.

14) Ashley SW, Wells SA Jr. Tumors of the small intestine. Semin Oncol 1988;15:116-128.

15) Coco C, Rizzo G, Manno A, Mattana C, Verbo A. Surgical treatment of small bowel neoplasms. Eur Rev Med Pharmacol Sci 2010;14:327-333.

16) Dhumane P, Mutter D, D'Agostino J, Mavrogenis G, Leroy J, Marescaux J. Small bowel exploration and resection using single-port surgery: a safe and feasible approach. Colorectal Dis 2013;15:109-114.

17) Lee WJ. Single port laparoscopic surgery. J Korean Med Assoc 2010;53:793-806.

18) Hayashi M, Asakuma M, Komeda K, Miyamoto $Y$, Hirokawa F, Tanigawa N. Effectiveness of a surgical glove port for single port surgery. World J Surg 2010;34:2487-9.

19) Goel R, Lomanto D. Controversies in single-port laparoscopic surgery. Surg Laparosc Endosc Percutan Tech 2012;22:380382. 